\section{Design and Performance Parameters of Photobioreactors}

\author{
by Clemens Posten, KIT
}

The design and development of photobioreactors is very important because the bioreactor is the technical centerpiece of the production of microalgae biomass. Apart from maximum production, other factors such as geometric and hydrodynamic parameters, measured performance criteria and mode and stability of operation, and cost effectiveness of the bioreactor need to be optimized. Clear criteria are missing for an assessment such as is needed to establish a uniform basis of data for sustainability and life-cycle assessments. Although several reactors will be presented in the following paper, the primary objective is to set the framework for such an assessment of photobioreactors. This begins in design features, but also goes beyond this to a definition of performance parameters, whose measurement is required and which ultimately determine whether the use of a reactor is successful.

\section{Introduction}

The current boom in microalgae biotechnology has led to a further strong increase in the expectation that the production of biofuels (methane, biodiesel, bioethanol) from microalgae will be sustainable both energetically and financially (Greenwell et al. 2009). The technical centerpiece of the production of microalgae biomass is naturally the photobioreactor. Several features for assessing a photobioreactor are given in the following. The algae boom in the past few years has led to an almost incomprehensible number of new types of reactors, and the operation of some of them has been terminated almost as quickly. Even today there is no precise scientific consensus as to how a photobioreactor is to be constructed. Precise studies of defined aspects are, in contrast to simple trial and error, still infrequent (e.g., Rosello Sastre 2007). Consensus has, however, been reached on several issues, although these points are not always taken into account (Pulz 2001; Janssen et al. 2003; Richmond 2004; Zijffers et al. 2008; Kunjapur et al. 2010; Morweiser et al. 2010). In this paper, several types of reactors will be presented, the primary objective being to set a framework for assessing photobioreactors.

\section{Direct Design Features}

In contrast to usual reactors, there must be a transparent surface in order to ensure the light influx reaches the contents. This results in two basic forms. Photobioreactors are divided into plate reactors and tubular reactors (fig. 1). Plate reactors are perfused with gas from the bottom to ensure the $\mathrm{CO}_{2}$ influx. The pneumatic energy brought in by the bubbles is converted into mechanical mixing energy. Circulation of the medium in tubular reactors is maintained by hydraulic pumps that provide the necessary mechanical energy. Gassing takes place at the beginning and end of a section of tube. Starting from these basic types, important design features and parameters for process engineering will be discussed below.

Fig. 1: Schematic image of the two basic types of reactors

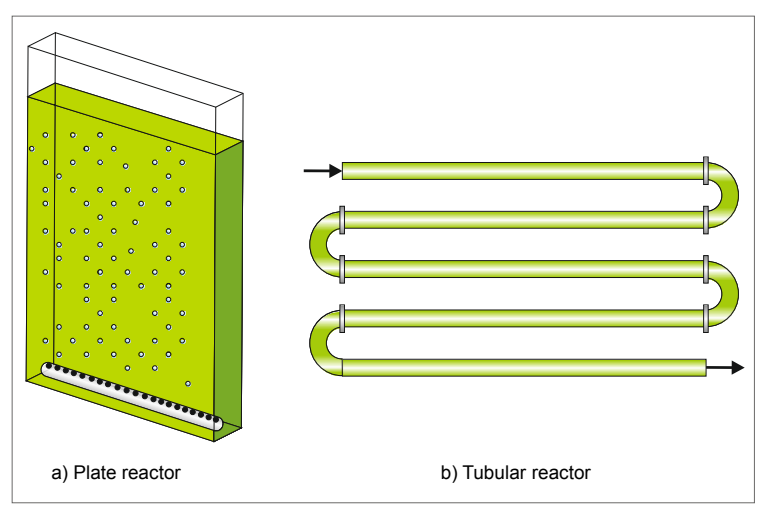

Source: Posten 2009

The possible transparent materials include glass, polyvinyl chloride (PVC), polyethylene (PE), polycarbonate (PC), acrylic (Plexiglas, PMMA), and silicate. PC exhibits good properties because of its high strength, the fact that it can be cleaned, and its weatherability, yet PE is preferred for practical reasons such as availability. Glass is preferred for high-quality applications but it is heavier and more complicated to process. Coatings are being discussed, for example a nonstick coating for indoors or a coating for IR reflection outside. A certain amount of material must be employed to main- 
tain mechanical stability and to accommodate the hydrostatic pressure. Yet for cost reasons (the material itself, its manufacture and transportation) this should be as minimal as possible. Furthermore, the use of the material enters into the consideration of the amount of energy used since, in terms of energy, only a limited recycling efficiency (transportation, reshaping) can be expected. From a harvest of biomass amounting to, for example, $20 \mathrm{~kg} / \mathrm{m}^{2} / \mathrm{a}$, approximately $10 \mathrm{~kg} \mathrm{C}$ is bound. This must naturally be clearly higher than the $\mathrm{CO}_{2}$ emitted during the manufacture of the reactor itself. There are hardly any actual values available from outdoor projects. Many reactors have to be supported by mechanical stands and must, furthermore, be under a roof or in a greenhouse to avoid weather-related contamination or damage as well as wind pressure. This results in costs and loss of light. Even a water basin can serve as a support for a floating plastic reactor (fig. 5).

\section{Geometric Parameters}

The primary difference between customary bioreactors for heterotrophic processes and photobioreactors is naturally the light influx through the transparent external walls (fig. 2). The relationship of the external surface area that is available to the volume that is supposed to be provided with light $A_{R} /$ $V_{R}$ is therefore an important factor. For a plate with a thickness $d$, for example, the relationship is $2 / d$. Common values are in the range from $50 \mathrm{~m}^{-1}$ to $100 \mathrm{~m}^{-1}$. Modern concepts go in the direction of larger values. The photosynthetic activity of algae is dependent on the strength of the light influx. At very small intensities of light $(<20 \mu \mathrm{E} /$ $\mathrm{m}^{2} / \mathrm{s}$ ), photosynthesis hardly surpasses cellular respiration. At small to medium intensities $(<200$

Source: Own compilation $\mu \mathrm{E} / \mathrm{m}^{2} / \mathrm{s}$ ), growth increases linearly with the intensity of the light. At high intensities, however, there is saturation or even photoinhibition. The actual amount of sunlight may exceed the critical value by a factor of 10-20 depending on the strain of algae, the time of day, the season, and the location. Any necessary dilution of the light can be achieved by increasing the design factor $A_{R} / A_{F}$ (surface area/ground surface area) of the transparent surface, whether by adjusting the vertical height or by employing fiber optic elements. Absorption and scattering weaken the light (exponentially) when it passes through the algae suspension, so that only a residual amount reaches the opposite wall. The distance that the light travels is referred to as the free optical path $\mathrm{d}_{\mathrm{L}}$. On the one hand, no light should be lost, while on the other no dark areas should occur in which algae do not grow and even lose cell weight just as a result of cellular respiration. The lower this value (thin layer), the higher the biomass concentration can be without creating a dark area that is too large. Naturally, a compromise has to be found for the given parameters since the amount of material increases with greater dilution of the light and with shorter optical paths. While the given parameters refer to the reactor's surface area, they also directly determine the volume of medium $V_{R}$ in the reactor and thus the amount of medium piled up on the ground area $A_{F}$. The parameter $V_{R} / A_{F}$ gives the amount of medium that is piled on the "footprint area". A typical value is 100

Fig. 2: Schematic outline of important parameters of a photobioreactor

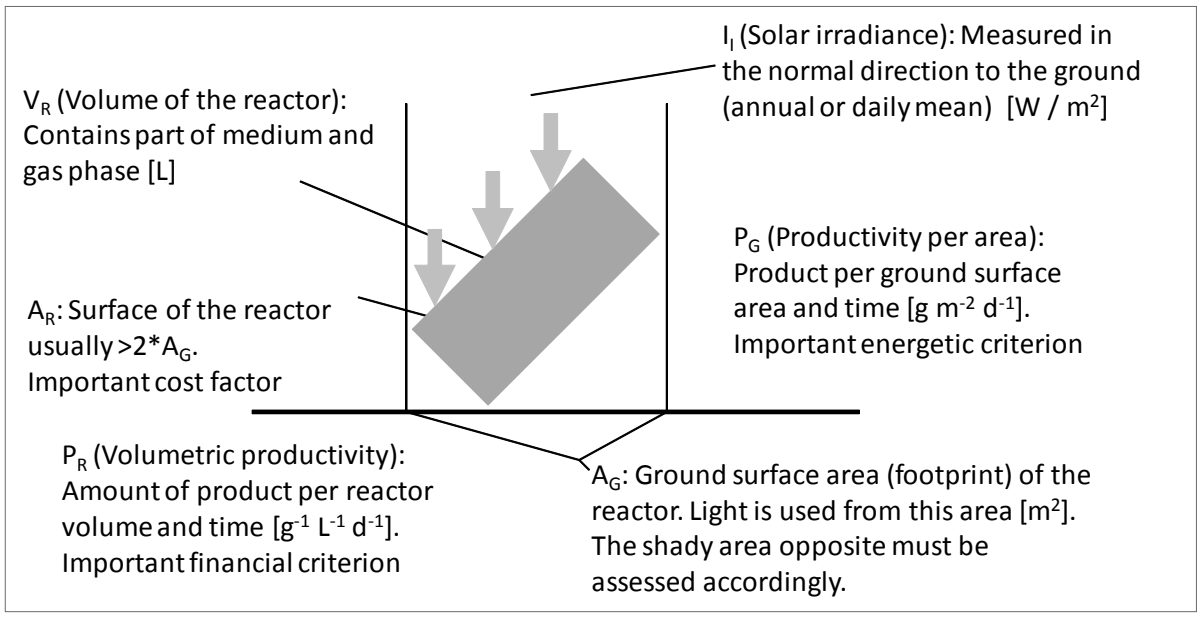


$\mathrm{L} / \mathrm{m}^{2}$. Higher values indicate a greater weight and a lower intensity of the process.

In principle, the volumetric productivity measured in the laboratory cannot simply be multiplied by the amount of medium since the amount of biomass produced per ground surface area is determined solely by the incident light. This mistake is made over and over again when the anticipated performance of reactors is predicted, leading to completely exaggerated expectations. The same false impression is produced by the statement that the volume of medium is necessarily the reaction volume. This tenet from classical reaction technology naturally cannot be applied in this case since only the cell volume can count as the reaction volume. It is furthermore counterproductive that a high volume of medium leads to a lower concentration of biomass and to a loss of energy, as is demonstrated in the following section.

\section{Hydrodynamic Parameters}

The pressure at the base of the reactor results from the hydrostatic pressure of the column of medium. It exerts a direct influence on the required strength of the transparent material and the energy needed to generate the bubbles. Both of these aspects do not cause any particular problem in classical reactors for heterotrophic products. In photobioreactors, however, this can become a problem because at higher pressures the qualities demanded of the material increase, as does, above all, the specific energy per volume or per area needed for gassing. As in any reactor, the contents must be mixed properly to prevent the formation of gradients. In the case of tubular reactors, the mixing time in the axial direction is the time the medium needs to be cycled one time through the tubes, which is the passage time between two gassing points (Hall et al. 2003) and thus is given by tube length and pumping velocity.

With increasing oxygen concentration and decreasing carbon dioxide concentration along the tube, the axial mixing time should not exceed, for example, $2 \mathrm{~min}$. In the case of plate reactors, mixing along the main axis, which in this case is the vertical axis, is given mainly by the vortices which are induced by the bubbles and the bubble rising time. Values for the dispersion coefficient in the range of $100 \mathrm{~s}$ are acceptable. The mixing time in the direction normal to the transparent surface (radial for tubes, thickness for plate) should not significantly exceed $1 \mathrm{~s}$ in order to utilize the fluctuating light effect, i.e., not to leave the cells in the particularly bright front areas or the dark back areas too long (Grobbelaar et al. 1996). A nontrivial amount of mechanical energy is however necessary to this end. The perfusion of a reactor in the axial direction is necessary in order to move the fluid from one gassing point to the next, sometimes exceeding $0.3 \mathrm{~m} / \mathrm{s}$ in tubular reactors. This, furthermore, also improves radial mixing (Molina et al. 2000; Perner-Nochta et al. 2007). In plate reactors, the bubbles induce circular flows that lead to axial perfusion rates of approximately $0.1 \mathrm{~m} / \mathrm{s}$, which can be significantly higher in certain specific designs. This results in acceptable axial dispersion coefficients (Camacho Rubio et al. 2004). Turbulent flow facilitates mixing in the normal direction (which is particularly necessary for high concentrations of cells), while laminar flow saves energy and is gentler on the cells. A fundamental consideration of hydrodynamics in photobioreactors can be found in Pruvost et al. (2011). Both open ponds and, even more so, enclosed bioreactors thus need auxiliary power essentially for mixing, gassing, and transport. In tubular reactors, more than 500 $\mathrm{W} / \mathrm{m}^{3}$ is customary (Babcock et al. 2002) with values between 200 and $400 \mathrm{~W} / \mathrm{m}^{3}$ being reported, while in plate reactors the lowest level is $50 \mathrm{~W} /$ $\mathrm{m}^{3}$ (Sierra et al. 2008). This last value increases, however, because of the increase in hydrostatic pressure with height in plate reactors. Because of its enclosed design, the pump energy in tubular reactors does not increase significantly with height.

It is important to understand that high values for productivity are often purchased by using high energy input to improve the light integration and gas input. For example, open ponds employ little auxiliary energy (e.g., $1 \mathrm{~W} / \mathrm{m}^{3}$ ) but their productivity is also correspondingly low. Current directions of research attempt to reach a low-energy mix by bundling the mechanical energy at certain frequencies that facilitate growth in the region of $10 \mathrm{~Hz}$. In the Airlift plate reactor of the firm subitec (Degen et al. 2001; Ripplinger 2009), directed vortices are created in the upstream area by using built-in baffles (fig. 3). 
Fig. 3: The Airlift plate reactor of the firm subitec

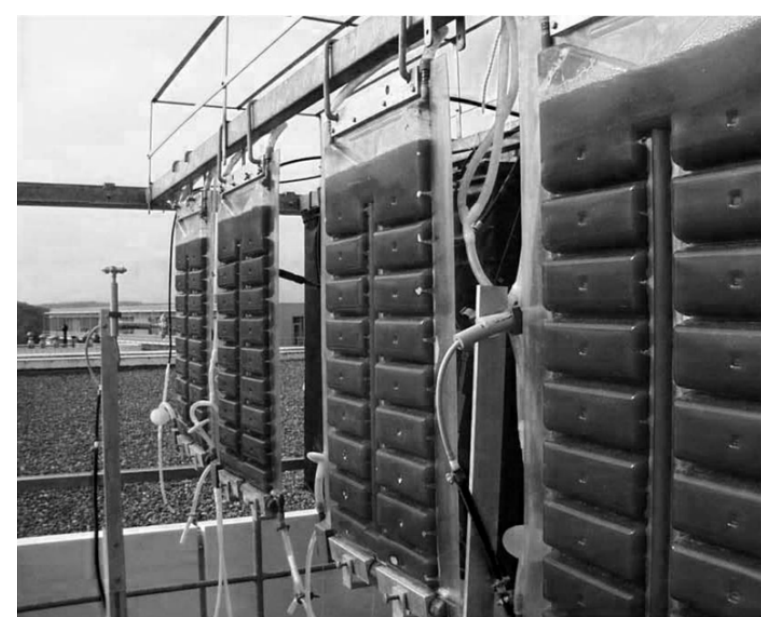

Source: Ripplinger 2009

Fig. 4: The novel principle of a tubular reactor ("Christmas Tree") of the firm Gicon

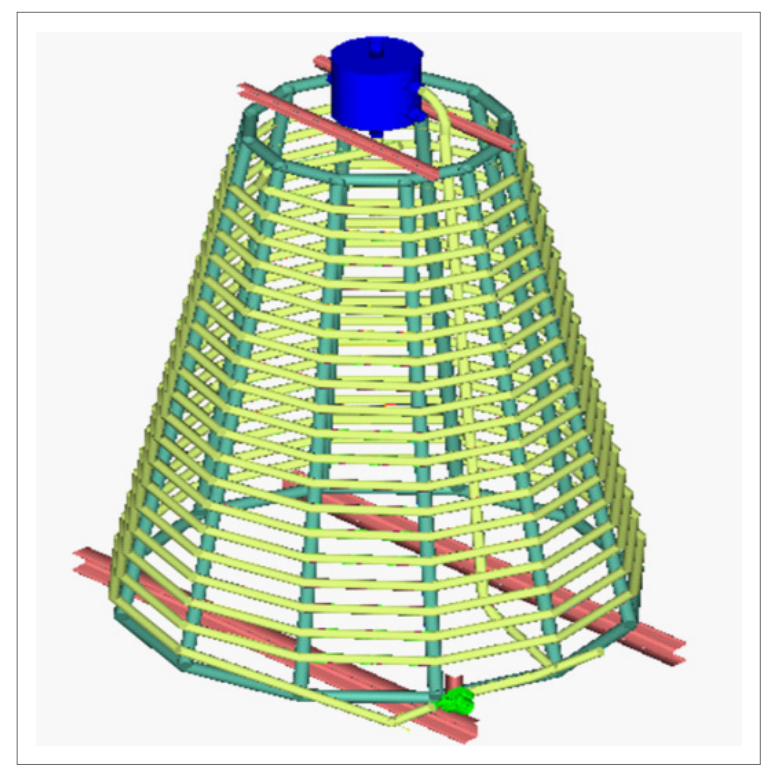

Source: Cotta 2011

The energy required for this is supposed to be reduced to $10 \mathrm{MJ} / \mathrm{kg}$ of produced algae biomass. The novel design of a tubular reactor ("Christmas Tree") of the firm Gicon (Cotta 2011) guarantees good exposure to light during the course of the day (fig. 4). Low energy input and a high dedicated radial mixing rate are produced by a novel pulsed procedure during gas inflow. This also prevents fouling on the tubular walls. Short light paths are achieved by using an internal tube which also maintains the correct temperature. Be- sides these concepts, the use of energy flows from the environment has been proposed, for example the use of wave energy at a NASA reactor (NASA 2011). It is hoped that a bubble-free gassing procedure can lead to another clear decline in pneumatic energy input (Fan et al. 2008; Posten 2009).

Photobioreactors are gassed with a mixture of air and $\mathrm{CO}_{2}$, the $\mathrm{CO}_{2}$ serving as the carbon source for the algae. The stoichiometric requirement is approximately 1.8 to $2 \mathrm{~g} \mathrm{CO}_{2}$ per gram of dry mass of algae created, depending on the lipid content. There must, however, be a sufficiently high partial pressure during the liquid phase so that the $\mathrm{CO}_{2}$ absorption by the algae is not limited (Yang et al. 2003) and light energy is not lost. The air portion serves to prevent gradients and blending. Customary values are $0.1 \mathrm{vvm}$ $\mathrm{CO}_{2}$ or even higher if flue gases (or other gases from fermentation or the chemical industry) are utilized. Reactors that are pumped directly can also be supplied with pure $\mathrm{CO}_{2}$. The parameters that can be used to assess this are the volumetric mass transfer coefficient ( $k_{\mathrm{L}} a$ value), the volumetric $\mathrm{CO}_{2}$ input rate (CTR) together with the corresponding $\mathrm{CO}_{2}$ production rate (OPR), and the degree of $\mathrm{CO}_{2}$ utilization. Open ponds have, for example, a relatively low need for auxiliary energy, yet their productivity is also low. There are hardly any systematically measured correlations between energy input and productivity.

\section{Measured Performance Criteria}

A high value for volumetric productivity measured as "space-time yield" is a sign of a reactor's intense operation. Yet it is not permissible to simply project laboratory values because an ideal supply of light is impossible on a large scale in outdoor operation. When sunlight is used, the energy input from light will not increase simply by piling up more medium on a certain ground surface area (see below on photoconversion energy, PCE). In the lab, only $1 \mathrm{~g} / \mathrm{L} / \mathrm{d}$ can be attained and only for mid-range concentrations of biomass. For photobioreactors operated only with sunlight, the decisive value is the solar irradiance per area, independent of the precise geometry. Here is a sample calculation. In central Europe, the entire energy falling on a square meter is, for example, 
$1200 \mathrm{kWh} / \mathrm{m}^{2} / \mathrm{a}$ or $4320 \mathrm{MJ} / \mathrm{m}^{2} / \mathrm{a}$. The energy in algae biomass is approximately $20 \mathrm{MJ} / \mathrm{kg}$. If the maximal PCE is $5 \%$, then we can reckon with a maximal biomass harvest of $30 \mathrm{~g} / \mathrm{m}^{2} / \mathrm{d}$ or $100 \mathrm{t} /$ ha/a. If the oil level is high, the energy in the algae climbs toward $27 \mathrm{MJ} / \mathrm{kg}$. Given the same PCE, the productivity of dry biomass per area thus sinks for thermodynamic reasons (Chisti 2008). Under no circumstances, thus, can the highest measured values for productivity and for oil level simply be multiplied to calculate the anticipated productivity for oil. For sunnier regions, the insolation from higher solar irradiation can be maximally a little more than twice as much. Reliable data on the actual productivity per area is only available for relatively few outdoor facilities, and then only for limited periods of a few weeks and areas of far less than 1 ha (e.g., Chini Zitelli et al. 2006). The data for the 1 ha facility in Klötze, Germany, given as $100 \mathrm{t} / \mathrm{ha} / \mathrm{a}$ (Roquette 2010) are frequently used as a reference value. Yet we must take into account that the culture is partially operated heterotrophically and therefore cannot serve as a standard for biofuel production. Furthermore, in terms of its investment costs and the energy required, the facility is designed for high-value products.

The greatest caution is necessary when a life-cycle assessment (LCA) is prepared using data from the Internet or other literature without having further background information. To assess the effectiveness of a reactor, the productivity has to be related to the radiant amount of light. The PCE (which should not be confused with photosynthetic efficiency or photon efficiency PE from biological studies) gives the relationship of the energy stored in the biomass to the radiant energy that reached the reactor's ground surface area. Optimistic values are $5 \%$, and values up to $10 \%$ are considered theoretically possible (Schenk et al. 2008; Chisti 2007; Zhu 2008). The higher the algae's oil content, the lower (reduction of up to $30 \%$ ) is the PCE (Wilhelm 2012). This value takes into account losses of light in the reactor itself, such as reflections on the surface or light that falls to the ground after passing between the individual modules of the reactor. This value is the ultimate standard for the efficiency of algal growth, but in some circumstances it is paid for by costs at diverse points (mixing, light dilution; see above).
This energy has to be deducted from the chemical product (biofuel) that is produced when the energy balance is determined. As described below, the energy flux that is produced can only amount to about $5 \mathrm{~W} / \mathrm{m}^{2}$ in the form of the heat of combustion. Given, for example, a performance input of $50 \mathrm{~W} / \mathrm{m}^{3}$ and medium amounting to $100 \mathrm{~L} / \mathrm{m}^{2}$, that amount would already be exhausted. Only a reactor that employs the absolute minimum for mixing energy - pneumatically for creating bubbles in a plate reactor and mechanical energy for pumping in a tubular reactor - can be used for the production of biofuels. One approach to such a minimization is to adjust the actual need for $\mathrm{CO}_{2}$ and the mixing intensity to the momentary consumption, which is permanently changing in response, for example, to the current position of the sun. It is extremely rare for genuine measurements of energy consumption for longer periods of cultivation to be available. At any rate, the amount of auxiliary energy is currently a reason obstructing the effective production of biofuels out of microalgae, but this is a topic that is the object of intense research. The concentration of biomass should in principle be as high as possible to make an intensive process possible. This also facilitates cell separation in the next step. Increasing the cell concentration for example from $1 \mathrm{~g} / \mathrm{L}$ to $2 \mathrm{~g} / \mathrm{L}$ reduces the fluid volume per amount of biomass to be fed through the centrifuge/filter by $50 \%$ and thus contributes decisively to reducing the costs downstream. Typical values are $<1 \mathrm{~g} / \mathrm{L}$ in open ponds and up to $5 \mathrm{~g} / \mathrm{L}$ in today's enclosed reactors. A value of 10 $\mathrm{g} / \mathrm{L}$ is desirable and feasible. Decisive for reaching this goal is not only the reactor geometry but also the strategies for feeding the medium.

\section{Mode and Stability of Operation}

The growth rate of microalgae is strongly dependent on the temperature. The mean temperatures in winter are too low and in summer too high because of the strong solar irradiance. Corrective actions could be a temperature-controlled greenhouse, installation in an artificial body of water to moderate the day-night temperature cycles, the use of IR-reflecting materials in the transparent body, and active cooling by spraying with water. The demonstration reactor "Water Bed" from Solix Biofuels 
(Solix 2011; Willson 2009) consists in principle of flat panels that are operated as bubble columns (fig. 5). The reactor unifies the ideas of low design height to minimize the energy input and a minimal use of material. The surrounding body of water serves as a support for the active elements and to balance variations in temperature. The submerged panels of the reactor "proviAPT" from the firm Proviron (Proviron 2011) functions similar to the Solix reactor, only that the individual elements are even lower and the surrounding body of water is itself contained by a plastic case (fig. 6). The company claims that the already low level of gassing energy is supposed to be lowered to less than 2 $\mathrm{W} \cdot \mathrm{m}^{-2}$. The investment costs amount to less than $20 € / \mathrm{m}^{2}$ for material weighing $2.5 \mathrm{~kg} / \mathrm{m}^{2}$.

It is, however, also possible to use the natural or available water currents, such as cool water from power stations or from bays. As a matter of principle, every action to actively moderate the temperature is tied to an extremely strong burden on the energy balance. This is a reason that locational advantages such as a constant air temperature tend to be taken into consideration, e.g., in southern countries but at a higher elevation above sea level. Locations in central Europe can in this regard have certain advantages because of the longer length of daylight in the summer (being shut down in the winter, which is possible if the investment costs are low; Posten, Schaub 2009). Most of today's production of algae is done in batch operation. The cells can increase to a certain cell concentration and then a large part of the suspension is harvested. The harvesting can take place late in the afternoon to minimize the nighttime respiratory-related loss of biomass. By the next midday the biomass concentration has increased enough again to absorb the strong daytime sunlight. Since the cells follow a circadian rhythm, the harvest cycle interacts with the cell division cycle, but these effects have not yet been understood scientifically. The goal of current research in this regard is to establish stable and continuous process operation.

Many algae cultures tend to stick to the walls. Proteins also deposit on the inside of the reactor. The problem can be controlled when the reactor is in operation but the reactor insides must be cleaned and hygienized (true sterilization is not possible)
Fig. 5: The schematic outline of the demonstration reactor "Water Bed" from Solix Biofuels

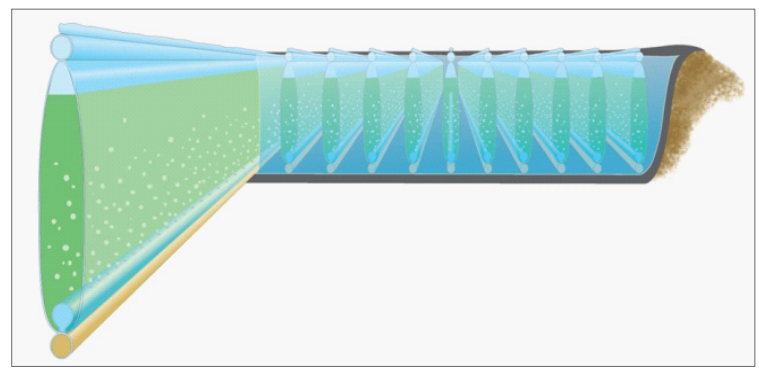

Source: Solix 2011

following a cultivation. Various liquids (sodium hydroxide, hydrogen peroxide) are used for this purpose. Such issues for establishing stabile cultures have played practically no role in scientific studies. At least one mechanical cleaning is essential, however, for the anticipated large-scale operation. "Pipeline pigs" are used for example in tubes. The insides of many of the available plate reactors cannot be cleaned. In some cases, the reactors are taken to be disposable. Although pilot plants in laboratories are still sterilized and can be operated (but not always) in an axenic manner (meaning in the absence of other organism), it cannot be assumed from the principles of today's reactors that the operation of large-scale production plants is free of contamination. Although inoculation from "seeding reactors" is possible, there will always be foreign pathogens in the system, such as bacteria, fungi, or competing microalgae. Countermeasures start with the biological system, such as by the selection of extreme operating conditions such as high $\mathrm{pH}$ or high salinity, in which contaminants do not thrive. The mode of operation can facilitate a low-pathogen manner of production, such as rapid growth and harvest cycles to prevent overgrowth or the realization of a plug-flow principle. Photobioreactors are in principle constructed modularly since the light input does not permit three-dimensional scale-up. The term "numbering up" is then used. Individual damaged or dirty modules must be easy to replace during maintenance of a facility. The specific costs of the reactor must be directly related to the costs of the amount of biomass produced. If for example $10 \mathrm{~kg}$ of algae are produced per year per $\mathrm{m}^{2}$ ground surface area, then proceeds of $5 € / \mathrm{m}^{2} / \mathrm{a}$ can be attained given a price 
Fig. 6: Submerged panels of the reactor "proviAPT" from the firm Proviron

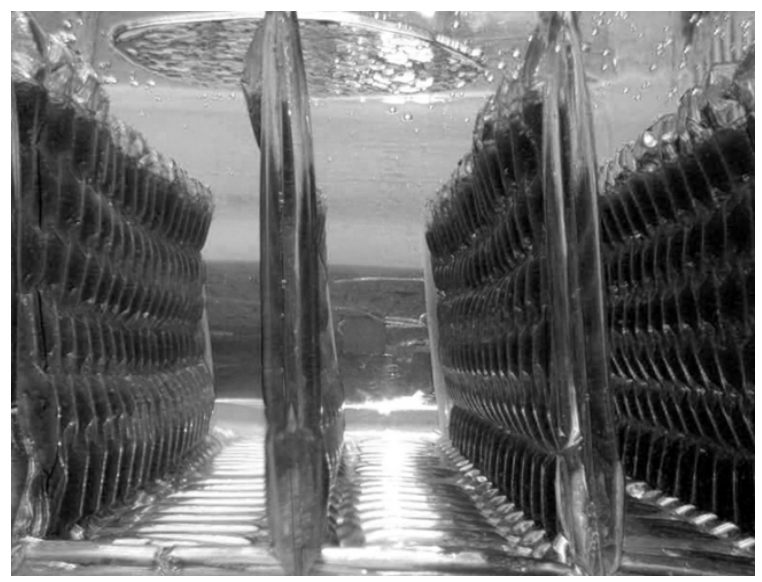

Source: Proviron 2011

of 50 cents $/ \mathrm{kg}$ (today's upper price for residual biomass for use as energy). Given an amortization of, for example, $10 \%$ per annum, the maximum price of the reactor would be $50 € / \mathrm{m}^{2}$. In this case, practically only simply designed plastic reactors come into question.

\section{Conclusion}

The design and development of photobioreactors for maximum production of algae is very important and detailed knowledge of light distribution, mass transfer, shear stress, scalability, and biology of algae cells is therefore required. Apart from maximum production, other factors such as design, cost effectiveness of the bioreactor, low maintenance costs, space convenience, and energy requirements need to be optimized. To date, none of the photobioreactors fulfill all the requirements. Overall it can be said that many of the attempts to produce lowcost biofuels in an energy-neutral manner by using microalgae have so far failed because of poor reactor engineering. Both the qualities demanded of the material as well as the auxiliary energy that is needed have been too high. Yet there are approaches to overcoming the bottlenecks afflicting existing photobioreactors and to developing innovative reactors that are beginning to directly take into consideration the needs of the production of energy carriers and the conditions at various locations. They are, however, often operated by indi- vidual institutes and small companies and not by large-scale collaborations such as we are used to in other areas of science. Besides, there is a lack of scientific consensus as to how a suitable and scalable photobioreactor is to be designed although the major factors affecting microalgae are well known.

\section{References}

Babcock, R.W.; Malda, J.; Radway, J.C., 2002: Hydrodynamics and Mass Transfer in a Tubular Airlift Photobioreactor. In: Journal of Applied Phycology 14/3 (2002), pp. 169-184

Camacho Rubio, F. et al., 2004: Mixing in Bubble Columns: A New Approach for Characterizing Dispersion Coefficients. In: Chemical Engineering Science 59/20 (2011), pp. 4369-4376

Chini Zittelli, G. et al., 2006: Productivity and Photosynthetic Efficiency of Outdoor Cultures of Tetraselmis suecica in Annular Columns. In: Aquaculture 261/3 (2006), pp. 932-943

Chisti, Y., 2007: Biodiesel from Microalgae. In: Biotechnology Advances 25/3 (2007), pp. 294-306

Chisti, Y., 2008: Biodiesel from Microalgae Beats Bioethanol. In: Trends in Biotechnology 26/3 (2008), pp. 126-131

Cotta, F., 2011: Ein innovatives Prinzip für tubuläre Photobioreaktoren. 5. Köthener Biotechnologie-Kolloquium, Köthen Germany

Degen, J. et al., 2001: A Novel Airlift Photobioreactor with Baffles for Improved Light Utilization Through the Flashing Light Effect. In: Journal of Biotechnology 92/2 (2001), pp. 89-94

Fan, L.-H. et al., 2008: Evaluation of a Membranesparged Helical Tubular Photobioreactor for Carbon Dioxide Biofixation by Chlorella vulgaris. In: Journal of Membrane Science 325/1 (2008), pp. 336-345

Greenwell, H.C.; Laurens, L.M.L.; Shields, R.J. et al., 2009: Placing Microalgae on the Biofuels Priority List: A Review of the Technological Challenges. In: Journal of the Royal Society Interface 7/46 (2010), pp. 703-726 Grobbelaar, J. U.; Nedbal, L.; Tichy, V., 1996: Influence of High Frequency Light/Dark Fluctuations on Photosynthetic Characteristics of Microalgae Photoacclimated to Different Light Intensities and Implications for Mass Algal Cultivation. In: Journal of Applied Phycology 8/4-5, pp. 335-343

Hall, D.O. et al., 2003: Outdoor Helical Tubular Photobioreactors for Microalgal Production: Modeling of Fluid-dynamics and Mass Transfer and Assessment of 
Biomass Productivity. In: Biotechnology and Bioengineering 82/1 (2003), pp. 62-73

Janssen M. et al., 2003: Enclosed Outdoor Photobioreactors: Light Regime, Photosynthetic Efficiency, Scale-up, and Future Prospects. In: Biotechnology and Bioengineering 81/2 (2003): pp. 193-210

Kunjapur, A.M.; Eldridge, R.B., 2010: Photobioreactor Design for Commercial Biofuel Production from Microalgae. In: Industrial \& Engineering Chemistry Research 49/8 (2010), pp. 3516-3526

Molina, E. et al., 2000: Tubular Photobioreactor Design for Algal Cultures. In: Journal of Biotechnology 92/2 (2001), pp. 113-131

Morweiser, M. et al., 2010: Developments and Perspectives of Photobioreactors for Biofuel Production. In: Applied Microbiology and Biotechnology 87/4 (2010), pp. 1291-1301

NASA - National Aeronautics and Space Administration,2011: OMEGA Project; http://www.nasa.gov/ centers/ames/research/OMEGA/index.html (download 5.4.12)

Perner-Nochta, I.; Posten, C., 2007: Simulations of Light Intensity Variation in Photobioreactors. In: Journal of Biotechnology 131/3 (2007), pp. 276-285

Posten, C., 2009: Design Principles of Photo-bioreactors for Cultivation of Microalgae. In: Engineering in Life Sciences 9/3 (2009), pp. 165-177

Posten, C.; Schaub, G., 2009: Microalgae and Terrestrial Biomass as Source for Fuels - A Process View. In: Journal of Biotechnology 142 /1 (2009), pp. 64-69 Proviron Industries NV, 2011: Latest ProviAPT Evolution Inaugurated. Hemiksem, Belgium; http://www. proviron.com/showcase/latest-proviapt-evolutioninaugurated (download 5.4.12)

Pruvost, J.; Van Vooren, G.; Le Gouic, B. et al., 2011: Systematic Investigation of Biomass and Lipid Productivity by Microalgae in Photobioreactors for Biodiesel Application. In: Bioresource Technology $102 / 1$ (2011), pp. 150-158

Pulz, O., 2001: Photobioreactors: Production Systems for Phototrophic Microorganisms. In: Applied Microbiology and Biotechnology 57/3 (2001), pp. 287-293

Richmond, A., 2004: Principles for Attaining Maximal Microalgal Productivity in Photobioreactors: An Overview. In: Hydrobiologia 512/1 (2004), pp. 33-37 Ripplinger, P.P., 2009: Industrielle Produktion von Mikroalgenbiomasse mit einem Flat-Panel-AirliftPhotobioreaktor. Köthen, Germany, 5. Köthener Biotechnologie-Kolloquium
Roquette Klötze GmbH \& Co. KG, 2010: Roquette Klötze $\mathrm{GmbH} \&$ Co. KG. Klötze, Germany; http://www. algomed.de/index.php?op=algenfarm (download 5.4.12)

Rosello Sastre, R.; Posten, C., 2007: Scale-down of Microalgae Cultivations in Tubular Photo-bioreactors - A Conceptual Approach. In: Journal of Biotechnology 132/2 (2007), pp. 127-133

Schenk, P.P.; Thomas-Hall, S.; Stephens, E. et al., 2008: Second Generation Biofuels: High-Efficiency Microalgae for Biodiesel Production. In: BioEnergy Research 1 /1 (2008), pp. 20-43

Sierra, E. et al., 2008: Characterization of a Flat Plate Photobioreactor for the Production of Microalgae. In: Chemical Engineering Journal 138/1-3 (2008), pp. 136-147

Solix Biofuels, 2011: Solix Biofuels; http://www.solixbiofuels.com (download 20.7.10)

Wilhelm, C.; Selmar, D., 2011: Energy Dissipation is an Essential Mechanism to Sustain the Viability of Plants. In: Journal of Plant Physiology 168 (2011), pp. 79-87

Willson, B., 2009: Low-Cost Photobioreactors for Production of Algae-Biofuels. 2009, GTOBiofuels: Science and Innovation for Sustainable Development Conference. San Francisco, CA

Yang, Y.; Gao, K., 2003: Effects of $\mathrm{CO}_{2}$ Concentrations on the Freshwater Microalgae, Chlamydomonas reinhardtii, Chlorella pyrenoidosa and Scenedesmus obliquus (Chlorophyta). In: Journal of Applied Phycology 15/5 (2003), pp. 379-389

Zhu, X.-G.; Long S.P.P.; Ort, D.R., 2008: What is the Maximum Efficiency with which Photosynthesis Can Convert Solar Energy into Biomass? In: Current Opinion in Biotechnology 19/2 (2008), pp. 153-159

Zijffers, J.-W. et al., 2008: Design Process of an AreaEfficient Photobioreactor. In: Marine Biotechnology 10/4 (2008), pp. 404-415

\section{Contact}

Prof. Dr.-Ing. Clemens Posten

Karlsruhe Institute of Technology (KIT)

Institute of Process Engineering in Life Sciences

Fritz-Haber-Weg 2, 76131 Karlsruhe, Germany

E-mail: clemens.posten@kit.edu 